Revista Destaques Acadêmicos, Lajeado, v. 8, n. 3, 2016. ISSN 2176-3070 DOI: http://dx.doi.org/10.22410/issn.2176-3070.v8i3a2016.1151 www.univates.br/revistas

\title{
POTENCIALIDADE DO TRABALHO DE INICIAÇÃO CIENTÍFICA JÚNIOR DO PROGRAMA PICMEL/FAPERGS/ CAPES NO TRABALHO COM PLANTAS MEDICINAIS
}

\author{
Mônica Jachetti Maciel ${ }^{1}$, Claudete Rempel ${ }^{2}$, Fabiana Heming Petry ${ }^{3}$, \\ Juciano Salvini ${ }^{4}$, Douglas Pessi ${ }^{5}$
}

Resumo: A iniciação científica é importante no processo de formação da vida escolar do estudante e no desenvolvimento da pesquisa e práticas de campo proporcionam o contato direto com o tema de estudo. Este artigo busca demonstrar a potencialidade do trabalho de iniciação científica júnior (BIC Jr.) de três alunos do Ensino Fundamental de uma escola pública de Lajeado/RS inseridos no Programa de Iniciação em Ciências, Matemática, Engenharias Criativas e Letras (PICMEL). Os BIC Jr. realizaram levantamento do cultivo e uso de plantas medicinais em 14 propriedades rurais produtoras de leite do Vale do Taquari/RS. Os resultados demonstram que 27 espécies de plantas medicinais são cultivadas nas propriedades, sendo que a família Asteraceae é a que apresenta o maior número de espécies (seis). O trabalho desenvolvido pelos estudantes pode torná-los líderes em suas escolas e propositores de diversas atividades como o plantio de canteiros de chás e ministrando palestras sobre as plantas estudadas.

Palavras-chave: BIC Jr. Sustentabilidade. Ervas Medicinais.

\section{INTRODUÇÃO}

As rápidas mudanças na sociedade, a globalização e a necessidade de formar profissionais capacitados para atuar com eficiência e qualidade necessita de um ensino cooperativo e que abra espaço para o desenvolvimento

1 Doutora em Medicina Veterinária. Docente do Centro de Ciências Biológicas e da Saúde e do Programa de Pós-Graduação em Sistemas Ambientais Sustentáveis.

2 Doutora em Ecologia. Docente do Centro de Ciências Biológicas e da Saúde e dos Programas de Pós-Graduação em Ambiente e Desenvolvimento e em Sistemas Ambientais Sustentáveis.

3 Bióloga. Professora Municipal.

4 Acadêmico do Curso de Ciências Biológicas, Licenciatura, do Centro Universitário UNIVATES.

5 Engenheiro Ambiental. 
de competências e habilidades. Preparar o profissional para enfrentar os desafios do mercado de trabalho e promover o desenvolvimento do aluno em conhecimento de diversas áreas, para atuar com competência em uma área específica deveria ser um dos objetivos do ensino (DEL PINO, 2013).

Segundo Cavalheiro e Del Pino (2007), um dos focos da aprendizagem dos alunos está no desenvolvimento de projetos interdisciplinares, espaços nos quais sentem-se mais responsáveis por interagir positivamente com outros alunos e com a comunidade pelo uso de fontes de informação diferentes das do ensino formal (como pessoas e recursos), tornando a inter-relação com pessoas um ato fundamental para o contínuo processo de aprendizagem. Em sentido amplo, as parcerias ocorrem desde o nosso nascimento, na família, entre os amigos, no ambiente de formação escolar inicial, no ambiente profissional, na sociedade como um todo. Mais do que nunca o homem deve se deixar mover pelo "ser social" que é (CAVALHEIRO; DEL PINO, 2007).

Os currículos escolares tradicionais, ainda predominantes nos níveis fundamental e médio, mostram pouca utilidade para a vida prática e a convivência social. Poucos qualificam para exercer qualquer profissão. Tampouco ajudam as pessoas a terem melhor atuação ou conduta em situações de vida social (BEAUCHAMP; PAGEL; NASCIMENTO, 2007). Fazemse necessários: raciocínio lógico, boa memória, capacidade de avaliação e discernimento, capacidade de síntese, capacidade de diálogo, observação, interação com outras pessoas, diferentes do convívio diário. Quanto mais se combinam ou se associam essas aptidões, mais aumenta o potencial de competência intelectual. Pode-se desenvolvê-las em conversas com pessoas diferentes, resumindo livros para aumentar a habilidade de síntese, realizando práticas laboratoriais e entendendo que é necessário aprender a conviver com o diferente, com dificuldades e imperfeições.

As metodologias educacionais que seguem o modelo tradicional podem não proporcionar um ambiente motivador e propício para o aluno gostar de aprender, pois muitas vezes falta espaço para a interação positiva entre alunos de diversas realidades e o desenvolvimento de habilidades interpessoais necessárias para uma participação construtiva no trabalho, comunidade e vida pessoal, as quais muitas vezes não são valorizadas. Cavalheiro (2007) considera que não é fácil educar alunos para uma sociedade que, se por um lado é pouco solidária e extremamente competitiva, por outro valoriza cada vez mais as parcerias estratégicas e o trabalho em equipe.

O educador deve orientar, estimular e preparar o educando para o desenvolvimento da autonomia intelectual. $\mathrm{O}$ professor tem hoje uma tarefa muito ampla: descentralizar as atividades didáticas, reorganizando a estrutura de ensino, no sentido de diminuir a quantidade de informações e aumentar o nível de aprendizagem. Acreditar, investir e dar suporte ao educando para que saiba selecionar o que é importante para sua atividade profissional e formação cultural (CAVALHEIRO; DEL PINO, 2007). 
A diversificação das modalidades didáticas na prática pedagógica pode atender a distintas necessidades e interesses dos alunos e contribuir para motivá-lo e envolvê-los no processo ensino/aprendizagem. A motivação é fundamental para que ocorra uma aprendizagem significativa e, além disso, não há um único caminho que conduza com segurança à aprendizagem, pois são inúmeras as variáveis que se interpõem nesse processo (VIVEIRO; DINIZ, 2009).

A partir deste contexto, propõe-se um fazer pedagógico que proporcione ao sujeito condições e atividades, que lhe permitam produzir seu próprio conhecimento, num processo de interação social. Dentre as diversas estratégias que o professor da área das Ciências pode recorrer (aulas expositivas, discussões, demonstrações, aulas práticas de laboratório, entre outras), a atividade de campo pode constituir uma excelente alternativa metodológica que permite explorar múltiplas possibilidades de aprendizagem dos alunos, desde que bem planejada e elaborada (VIVEIRO; DINIZ, 2009).

Para Compiani (1991), o campo é um excelente "ambiente de ensino", que pode auxiliar na aprendizagem dos alunos, visto que proporciona o contato direto com os objetos e os fenômenos concretos que estão sendo estudados. $\mathrm{O}$ contato direto com o meio é uma das características que tornam as atividades de campo essenciais, permitindo que o aluno perceba os fenômenos em sua interação e a natureza não fragmentada, mas reconhecer as relações que existem, que se concretizam. Conforme Fantinel (2000) no ensino, o papel das atividades de campo está atrelado à proposta pedagógica da disciplina ou projeto na qual as atividades se inserem e à concepção do professor acerca do que é ensinar, do que é aprender e de seu entendimento de como se processa o conhecimento.

Proporcionar ao aluno a oportunidade de trabalhar e interagir com a comunidade, com produtores rurais é um desafio. Através da cooperação no cotidiano pode-se criar um ambiente de ajuda mútua, respeito pelas diferenças e responsabilidade compartilhada, podendo desenvolver as habilidades sociais que objetivamos no projeto de pesquisa. O educando possui necessidade de entender o funcionamento do mundo. $\mathrm{O}$ educador deve orientar, estimular e despertar para a investigação, deve orientar sua prática para que o educando desenvolva a expressividade, a emoção, a personalidade e o pensamento criativo (LOPES, 2008). Desta forma, o educando estará sendo preparado para o desenvolvimento da autonomia intelectual.

Algumas das temáticas que foram trabalhadas neste projeto englobam competências e habilidades, formação intelectual, autonomia, interpretação e linguagem. Existe a expectativa de que os alunos que compuseram do grupo de pesquisa, participando das atividades de campo, entrevistas e práticas laboratoriais, levem esta experiência aos demais colegas, que incitarão discussões e ações que proporcionará produções sobre os conhecimentos construídos. É provável que as práticas melhorem a confiança em si mesmos e proporcionem 
situações novas de ação. E em relação aos alunos há possibilidades de melhoria de aprendizagem e motivação.

As práticas de campo são uma ótima metodologia de ensino, capaz de auxiliar na aprendizagem dos alunos, por proporcionar o contato direto com plantas e seus cultivos, como é o presente caso. Este trabalho busca demonstrar a potencialidade do trabalho de iniciação científica júnior (BIC Jr.) de três alunos do Ensino Fundamental de uma escola pública de Lajeado/RS, inseridos no Programa de Iniciação em Ciências, Matemática, Engenharias Criativas e Letras (PICMEL/FAPERGS/CAPES) desenvolvido no Centro Universitário UNIVATES, de novembro de 2014 a outubro de 2015.

\section{PROCEDIMENTOS METODOLÓGICOS}

O Programa de Iniciação em Ciências, Matemática, Engenharias Criativas e Letras (PICMEL/FAPERGS/CAPES) iniciou em novembro de 2014, sendo que o projeto de pesquisa "Trabalhando com sustentabilidade ambiental em propriedades rurais produtoras de leite do Vale do Taquari", da Univates, foi um dos projetos aprovados pelo programa. Para este projeto foram selecionados seis bolsistas da Educação Básica Pública do município de Lajeado (três do Ensino Fundamental e três do Ensino Médio). As atividades aqui relatadas são dos três Bolsistas de Iniciação Científica Júnior (BIC Jr) e da professora orientadora de uma escola municipal de ensino fundamental. O projeto de pesquisa aprovado pelo PICMEL teve como objetivo construir e avaliar com os professores das escolas envolvidas uma metodologia para análise química da água (atividade desenvolvida pelos alunos bolsistas do Ensino Médio) das propriedades rurais que trabalham com a produção leiteira e identificação das espécies de plantas medicinais presentes nestas propriedades, fazendo com que os alunos envolvidos possam realizar estas atividades em suas escolas, disseminando a metodologia e o conhecimento adquirido com demais colegas e professores.

Para o desenvolvimento destas atividades, os BIC Jr. e sua professora orientadora encontravam-se um turno por semana, em sala da Univates, com os pesquisadores e Bolsistas de Iniciação Científica (BIC) do grupo de pesquisa e em outro turno ou desenvolviam atividades em suas escolas ou realizavam saídas a campo para as propriedades rurais produtoras de leite participantes da pesquisa.

Todos os encontros, que ocorreram no período de um ano, foram pensados e planejados buscando desenvolver nos alunos o interesse pela pesquisa e pelo conhecimento. Inicialmente, foram ministradas algumas aulas teóricas para conhecimento da taxonomia das plantas, com vídeos, palestras, aulas práticas no laboratório didático de biologia, leituras de livros e artigos referentes ao tema. Também foram realizadas visitas aos produtores rurais para identificação das plantas das propriedades. Em atividades extraclasse, 
os alunos revisavam temas e assuntos vistos na universidade, aprofundando dessa forma, os seus conhecimentos.

Os BIC Jr. estudaram a forma correta de identificação das espécies de plantas medicinais presentes nestas propriedades. Para tanto, os alunos buscaram artigos científicos e pesquisas referentes às plantas medicinais, leram, montaram resumos e fizeram apresentações para os demais participantes da pesquisa e também para alunos da escola. A partir dessas leituras, elaboraram um roteiro de questões a serem perguntadas aos produtores rurais visitados. As questões foram:

1. Qual o local na propriedade onde estas plantas são cultivadas?

2. Quais as partes das plantas usadas para fins medicinais?

3. Qual a forma de preparo, indicações de uso, tipos de plantas presentes na propriedade?

4. Qual o modo de obtenção das mesmas?

Depois fizeram coletas das plantas medicinais nas propriedades. As plantas que não foram identificadas em campo foram coletadas, desidratadas e herborizadas para posterior identificação. As exsicatas foram depositadas no Herbário do Vale do Taquari (HVAT) do Museu de Ciências Naturais da Univates. A identificação das espécies foi realizada com o uso de bibliografias específicas e de consulta a especialistas. Ao final, os BIC Jr. montaram um herbário que foi levado para as escolas e também reativaram o "Canteiro dos Chás" que existia plantando as espécies encontradas na pesquisa.

\section{RESULTADOS E DISCUSSÃO}

Durante os 12 meses de desenvolvimento das atividades do PICMEL, os BIC Jr. visitaram 14 propriedades rurais produtoras de leite do Vale do Taquari /RS. Nestas visitas foram identificadas 51 espécies de 28 famílias. A maior ocorrência de espécies foi da família Asteraceae, com 11 espécies, seguida da família Lamiaceae com cinco espécies e Rutaceae com quatro espécies. A família Myrtaceae contara com três espécies e as famílias Alliaceae, Apiaceae, Malvaceae e Verbenaceae com duas espécies e ainda há outras 20 famílias com apenas uma espécie (TABELA 1). 
Tabela 1 - Família, espécie, nome popular e utilização medicinal das plantas medicinais cultivadas e utilizadas por produtores rurais do Vale do Taquari/ RS (seguindo nomenclatura e descrição de Lorenzi e Matos (2008))

\begin{tabular}{|c|c|c|c|}
\hline Família & Espécie & Nome popular & Utilização medicinal \\
\hline Adiantaceae & $\begin{array}{l}\text { Adiantum capillus- } \\
\text { veneris } \mathrm{L} \text {. }\end{array}$ & Avenca & $\begin{array}{l}\text { Alcoolismo, amenorreia, asma, bronquites, } \\
\text { caspa, catarro, congestão, dor de garganta, } \\
\text { enfisema, febre, fraqueza renal, icterísica, } \\
\text { laringite, tosse, vermes. }\end{array}$ \\
\hline Alismataceae & $\begin{array}{l}\text { Echinodorus } \\
\text { grandiflorus (Cham. } \\
\text { \& Schltdl.) Micheli }\end{array}$ & $\begin{array}{l}\text { Chapéu-de- } \\
\text { couro }\end{array}$ & $\begin{array}{l}\text { Diurético, depurativo do organismo, } \\
\text { cataplasma para hérnias. }\end{array}$ \\
\hline \multirow{2}{*}{ Alliaceae } & Allium fistolosum L. & Cebolinha & $\begin{array}{l}\text { Perturbações intestinais, edema, gripe, } \\
\text { trombose, arteriosclerose. }\end{array}$ \\
\hline & Allium sativum $\mathrm{L}$. & Alho & $\begin{array}{l}\text { Perturbações intestinais, edema, gripe, } \\
\text { trombose, arteriosclerose. }\end{array}$ \\
\hline Amaranthaceae & $\begin{array}{l}\text { Alternanthera } \\
\text { brasiliana L. Kuntze }\end{array}$ & Sempre-viva & $\begin{array}{l}\text { Antitumoral, diurética, digestiva, } \\
\text { depurativa, moléstias do fígado e da } \\
\text { bexiga. }\end{array}$ \\
\hline \multirow[b]{2}{*}{ Apiaceae } & $\begin{array}{l}\text { Foeniculum vulgare } \\
\text { Mill. }\end{array}$ & $\begin{array}{l}\text { Erva-doce, } \\
\text { Funcho }\end{array}$ & $\begin{array}{l}\text { Problemas digestivos, eliminar gases, } \\
\text { combater cólicas, estimular lactação. }\end{array}$ \\
\hline & $\begin{array}{l}\text { Petroselinum } \\
\text { crispum (Mill.) Fuss }\end{array}$ & Salsa & 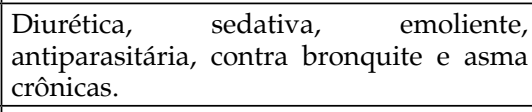 \\
\hline Asphodelaceae & $\begin{array}{l}\text { Aloe vera (L.) Burm. } \\
\text { f. }\end{array}$ & Babosa & $\begin{array}{l}\text { Trato dos cabelos, cicatrizante, ação } \\
\text { antimicrobiana. }\end{array}$ \\
\hline \multirow{5}{*}{ Asteraceae } & $\begin{array}{l}\text { Achillea millefolium } \\
\text { L. }\end{array}$ & $\begin{array}{l}\text { Mil-folhas, } \\
\text { novalgina }\end{array}$ & $\begin{array}{l}\text { Diurética, anti-inflamatória, } \\
\text { antiespasmódica e cicatrizante. }\end{array}$ \\
\hline & $\begin{array}{l}\text { Achyrocline } \\
\text { satureioides (Lam.) } \\
\text { DC }\end{array}$ & $\begin{array}{l}\text { Marcela ou } \\
\text { macela }\end{array}$ & $\begin{array}{l}\text { Problemas gástricos, epilepsia e cólicas } \\
\text { de origem nervosa. Anti-inflamatório, } \\
\text { antiespasmódico e analgésico, para } \\
\text { diarreia e disenteria. }\end{array}$ \\
\hline & $\begin{array}{l}\text { Artemisia } \\
\text { absinthium L. }\end{array}$ & Losna & $\begin{array}{l}\text { Diurética, abortiva, anti-helmíntica, } \\
\text { aumenta o peristaltismo intestinal. }\end{array}$ \\
\hline & $\begin{array}{l}\text { Baccharis trimera } \\
\text { (Less.) DC. }\end{array}$ & Carqueja & $\begin{array}{l}\text { Problemas hepáticos, contra disfunções } \\
\text { estomacais e intestinais. Tratamento de } \\
\text { úlceras e diabetes. }\end{array}$ \\
\hline & $\begin{array}{l}\text { Chamomilla recutia } \\
\text { (L.) Rauschert }\end{array}$ & Camomila & $\begin{array}{l}\text { Digestivo, calmante, sedativo, eliminação } \\
\text { de gases, combate a cólicas e estimular o } \\
\text { apetite. }\end{array}$ \\
\hline
\end{tabular}




\begin{tabular}{|c|c|c|c|}
\hline Família & Espécie & Nome popular & Utilização medicinal \\
\hline \multirow{6}{*}{ Asteraceae } & Cynara scolymus L. & Alcachofra & $\begin{array}{l}\text { Ativar a vesícula, proteger o fígado, baixar } \\
\text { o colesterol e hipoglicêmico, melhorar } \\
\text { o funcionamento dos rins, facilitar a } \\
\text { digestão e eliminar pedras nos rins. }\end{array}$ \\
\hline & $\begin{array}{l}\text { Helianthus annuus } \\
\text { L. }\end{array}$ & Girassol & $\begin{array}{l}\text { Diurética, expectorante, tratamento de } \\
\text { afecções dos brônquios e da laringe. } \\
\text { Laxante suave. }\end{array}$ \\
\hline & $\begin{array}{l}\text { Mikania glomerata } \\
\text { Spreng. }\end{array}$ & Guaco & $\begin{array}{l}\text { Ação tônica, depurativa, febrífuga } \\
\text { e peitoral, estimulante do apetite e } \\
\text { antigripal. Utilizado para gargarejos nas } \\
\text { afecções da garganta e boca. }\end{array}$ \\
\hline & $\begin{array}{l}\text { Solidago chilensis } \\
\text { Meyen }\end{array}$ & Arnica-brasileira & Curativa de feridas e chagas. \\
\hline & $\begin{array}{l}\text { Tanacetum vulgare } \\
\text { L. }\end{array}$ & $\begin{array}{l}\text { Catinga de } \\
\text { mulata }\end{array}$ & $\begin{array}{l}\text { Espantar moscas, afugentar traças e } \\
\text { repelir pulgas, anti-helmíntica, abortiva, } \\
\text { digestiva. }\end{array}$ \\
\hline & $\begin{array}{l}\text { Vernonia condensata } \\
\text { Baker }\end{array}$ & Boldo & $\begin{array}{l}\text { Supressão de gases intestinais, } \\
\text { insuficiência hepática e inflamação na } \\
\text { vesícula. Analgésico. }\end{array}$ \\
\hline Boraginaceae & $\begin{array}{l}\text { Symphytum } \\
\text { officinale L. }\end{array}$ & Confrei & $\begin{array}{l}\text { Doenças gastrointestinais, disenterias, } \\
\text { inflamações, reumatismo, hemorroidas, } \\
\text { tosse, bronquite e irregularidades } \\
\text { menstruais. }\end{array}$ \\
\hline Brassicaceae & $\begin{array}{l}\text { Nasturtium } \\
\text { officinale R. Br. }\end{array}$ & Agrião & $\begin{array}{l}\text { Estimulante de órgãos digestórios, } \\
\text { diurética e vermífuga, combate do } \\
\text { raquitismo, contra atonia intestinal. Como } \\
\text { cataplasma é utilizado na cicatrização de } \\
\text { feridas. }\end{array}$ \\
\hline Celastraceae & $\begin{array}{l}\text { Maytenus ilicifolia } \\
\text { (Schrad.) Planch. }\end{array}$ & $\begin{array}{l}\text { Espinheira santa, } \\
\text { cancorosa }\end{array}$ & $\begin{array}{l}\text { Problemas estomacais (gastrite e úlcera), } \\
\text { tratamento do câncer, antibiótico e } \\
\text { antileucêmica. }\end{array}$ \\
\hline Costaceae & $\begin{array}{l}\text { Costus spicatus } \\
\text { (Jacq.) Sw. }\end{array}$ & Cana-de-macaco & $\begin{array}{l}\text { Depurativa, adstringente e diurética. } \\
\text { Utilizado para tratamento da gonorreia, } \\
\text { sífilis, nefrite, picadas de insetos, } \\
\text { problemas de bexiga e diabetes. }\end{array}$ \\
\hline Curcubitaceae & $\begin{array}{l}\text { Sechium edule } \\
\text { (Jacq.) Sw. }\end{array}$ & Chuchu & $\begin{array}{l}\text { Diurético, hipotensor e remineralizante. } \\
\text { Hipotensivo }\end{array}$ \\
\hline Ebenaceae & Diospyros kaki L. & Caqui & $\begin{array}{l}\text { Afecções do fígado, problemas intestinais, } \\
\text { catarros da bexiga e as enfermidades das } \\
\text { vias respiratórias. }\end{array}$ \\
\hline Equisetaceae & $\begin{array}{l}\text { Equisetum } \\
\text { giganteum } \mathrm{L} .\end{array}$ & Cavalinha & $\begin{array}{l}\text { Adstringente, diurética e estíptica, } \\
\text { tratamento da gonorreia, diarreia e } \\
\text { infecção dos rins e bexiga. }\end{array}$ \\
\hline Euphorbiaceae & Ricinus communis L. & Mamona & $\begin{array}{l}\text { Tratamento de furúnculos, abcessos e } \\
\text { inflamação no ouvido médio. }\end{array}$ \\
\hline Gentianaceae & $\begin{array}{l}\text { Simaba ferrugínea } \\
\text { A. St.-Hil. } \\
\end{array}$ & \begin{tabular}{|l|}
$\begin{array}{l}\text { Fel-da-terra, } \\
\text { calunga }\end{array}$ \\
\end{tabular} & $\begin{array}{l}\text { Redução do prolapso do intestino reto e } \\
\text { para cicatrização de ferimentos }\end{array}$ \\
\hline \multirow{2}{*}{ Lamiaceae } & Mentha pulegium L. & Poejo & $\begin{array}{l}\text { Tratamento de bronquite catarral crônica } \\
\text { e asmática, coqueluche, leucorreia e } \\
\text { disminorreia. Tratamento de afecções da } \\
\text { pele }\end{array}$ \\
\hline & Mentha spp. & Hortelã, menta & $\begin{array}{l}\text { Antidispéptica, antivomitiva, descon- } \\
\text { gestionante nasal e antigripal, alívio da } \\
\text { dor de cabeça, coceira na pelo. }\end{array}$ \\
\hline
\end{tabular}




\begin{tabular}{|c|c|c|c|}
\hline Família & Espécie & Nome popular & Utilização medicinal \\
\hline \multirow{3}{*}{ Lamiaceae } & Origanum vilgare $\mathrm{L}$. & $\begin{array}{l}\text { Manjerona, } \\
\text { orégano }\end{array}$ & $\begin{array}{l}\text { Estimulante do sistema nervoso, forte } \\
\text { ação analgésica, espasmolítia, suforífica, } \\
\text { estimulante da digestão e da atividade } \\
\text { uterina, expectorante brando. Tratar } \\
\text { gripes, resfriados, indigestão, flatulência, } \\
\text { distúrbios estomacais e de cólicas } \\
\text { menstruais }\end{array}$ \\
\hline & $\begin{array}{l}\text { Rosmarinus } \\
\text { officinalis L. }\end{array}$ & Alecrim & $\begin{array}{l}\text { Má digestão, dor de cabeça. Dismenorreia, } \\
\text { fraqueza, memória fraca. Tratamento da } \\
\text { hipertensão, problemas digestivos, perda } \\
\text { de apetite e sintomas de reumatismo. }\end{array}$ \\
\hline & Salvia officinalis L. & Sálvia & $\begin{array}{l}\text { Indigestão, problemas do fígado, lactação, } \\
\text { salivação e suor excessivos, contra } \\
\text { ansiedade, depressão e problemas de } \\
\text { menopausa. }\end{array}$ \\
\hline \multirow{2}{*}{ Malvaceae } & $\begin{array}{l}\text { Hibiscus sabdariffa } \\
\text { Lineo }\end{array}$ & Hibisco & $\begin{array}{l}\text { Problemas digestivos-estomacais, } \\
\text { refrescante intestinal, diurético e protetor } \\
\text { das mucosas }\end{array}$ \\
\hline & Malva sylvestris L. & Malva & $\begin{array}{l}\text { Bronquite crônica, tosse, asma, enfisema } \\
\text { pulmonar, coqueluche, colite e constipação } \\
\text { intestinal. Laxativo }\end{array}$ \\
\hline \multirow{3}{*}{ Myrtaceae } & $\begin{array}{l}\text { Campomanesia } \\
\text { xanthocarpa } \mathrm{O} \text {. Berg }\end{array}$ & Guabiroba & $\begin{array}{l}\text { Tratar catarros, diarreia e disenteria. } \\
\text { Elimina colesterol e fortalece a memória }\end{array}$ \\
\hline & Eucalyptus spp. & Eucalipto & \begin{tabular}{|lll}
$\begin{array}{l}\text { Anticatarral, tratamento } \\
\text { congestão nasal e sinusite. }\end{array}$ & da gripe, \\
\end{tabular} \\
\hline & Psidium guajava L. & Goiaba vermelha & $\begin{array}{l}\text { Bochechos e gargarejos. Lavagens locais } \\
\text { de úlceras e na leucorreia. Diarreia e } \\
\text { reidratante caseiro. }\end{array}$ \\
\hline Phyllanthaceae & $\begin{array}{l}\text { Phyllanthus niruri } \\
\text { L. }\end{array}$ & Quebra-pedra & $\begin{array}{l}\text { Litíase renal, reumatismo gotoso e outras } \\
\text { afecções caracterizadas por taxas elevadas } \\
\text { de ácido úrico. }\end{array}$ \\
\hline Phytotaccaceae & Petiveria alliaceae $\mathrm{L}$. & Guiné & $\begin{array}{l}\text { Antiespasmódica, diurética e sudorífica. } \\
\text { Utilizada no tratamento de artrite, } \\
\text { reumatismo, malária, memória fraca e } \\
\text { para induzir abortos. }\end{array}$ \\
\hline Plantaginaceae & Plantago major $\mathrm{L}$. & Tansagem & $\begin{array}{l}\text { Contra afecções da pele (acnes e espinhas). } \\
\text { Contra amigdalite, faringite, gengivite, } \\
\text { estomatite e traqueíte e desintoxicante das } \\
\text { vias respiratórias de fumantes. }\end{array}$ \\
\hline Poaceae & $\begin{array}{l}\text { Cymbopogon } \\
\text { citratus }\end{array}$ & $\begin{array}{l}\text { Erva-cidreira, } \\
\text { Capim-cidreira }\end{array}$ & $\begin{array}{l}\text { Alívio de pequenas crises de cólicas } \\
\text { uterinas e intestinais, tratamento do } \\
\text { nervosismo e estados de intranquilidade, } \\
\text { analgésico e antimicrobiano. }\end{array}$ \\
\hline Rosaceae & Prunus domestica L. & Ameixa & $\begin{array}{l}\text { Ativador das funções hepáticas, digestivo, } \\
\text { refrigerante, laxativo, para tosse e prisão } \\
\text { de ventre. }\end{array}$ \\
\hline Rutaceae & $\begin{array}{l}\text { Citrus limon (L.) } \\
\text { Burn. f. }\end{array}$ & Limão & $\begin{array}{l}\text { Diurético, antiescorbútico, antirreumático, } \\
\text { antidesintérico, adstringente e febrífuga. } \\
\text { Contra acidez estomacal, ácido úrico, } \\
\text { varizes, hemorroidas, Pedro nos rins, } \\
\text { congestão dos brônquios, eczema, dor de } \\
\text { garganta, picada de inseto e gripe. }\end{array}$ \\
\hline
\end{tabular}




\begin{tabular}{|c|c|c|c|}
\hline Família & Espécie & Nome popular & Utilização medicinal \\
\hline \multirow{3}{*}{ Rutaceae } & $\begin{array}{l}\text { Citrus sinensis (L.) } \\
\text { Osbeck }\end{array}$ & Laranja & $\begin{array}{l}\text { Analgésica, antielmíntica, antiemorrágica, } \\
\text { antirreumática, antitérmica, calmante } \\
\text { do sistema nervoso, ciática, depurativa, } \\
\text { diurética, estimulante, laxante, regulador } \\
\text { intestinal, sudorífera, tônica }\end{array}$ \\
\hline & $\begin{array}{l}\text { Fortunella margarita } \\
\text { S. }\end{array}$ & Laranjinha & $\begin{array}{l}\text { Analgésica, antielmíntica, antiemorrágica, } \\
\text { antirreumática, antitérmica, calmante } \\
\text { do sistema nervoso, ciática, depurativa, } \\
\text { diurética, estimulante, laxante, regulador } \\
\text { intestinal, sudorífera, tônica }\end{array}$ \\
\hline & Ruta graveolens L. & Arruda & $\begin{array}{l}\text { Desordens menstruais, inflamações na } \\
\text { pele, dor de ouvido, dor de dente, febre, } \\
\text { câimbras, doenças do fígado, verminose e } \\
\text { como abortivo. }\end{array}$ \\
\hline Urticaceae & Urtica dioica $\mathrm{L}$. & Urtiga, Urtigão & $\begin{array}{l}\text { Propriedades antirreumática, antisséptica, } \\
\text { bactericida, adstringente, diurético- } \\
\text { depurativo, estimulante circulatório, } \\
\text { antianêmico, emenagogo, afrodisíago, } \\
\text { hemostático, hipoglicêmico, hipotensivo, } \\
\text { estomáquico, vasodilatador e vermífugo. }\end{array}$ \\
\hline \multirow{2}{*}{ Verbenaceae } & $\begin{array}{l}\text { Aloysia triphylla } \\
\text { Royle }\end{array}$ & $\begin{array}{l}\text { Cidró, Cidrão, } \\
\text { Erva-luísa }\end{array}$ & $\begin{array}{l}\text { Age como sedativo brando, reduzindo } \\
\text { febres e aliviando } \text { espasmos, } \\
\text { especialialmente os do sistema } \\
\text { digestive. Inseticida e bactericida. } \\
\text { Antiespmasmódicae calmante }\end{array}$ \\
\hline & $\begin{array}{l}\text { Lippis alba (Mill.) } \\
\text { N. E. Br. }\end{array}$ & $\begin{array}{l}\text { Sálvia da gripe, } \\
\text { falsa melissa, } \\
\text { erva cidreira-de- } \\
\text { arbusto }\end{array}$ & $\begin{array}{l}\text { Alívio de pequenas crises de cólicas } \\
\text { uterinas e intestinais, tratamento do } \\
\text { nervosismo e estados de intranquilidade }\end{array}$ \\
\hline Zingibrenaceae & $\begin{array}{l}\text { Zingiber officinale } \\
\text { Roscoe }\end{array}$ & Gengibre & $\begin{array}{l}\text { Estimulantedigestive, dyspepsia, calmante } \\
\text { de cólicas flatulentes, ação antimicrobiana } \\
\text { local, combate a rouquidão e inflamação } \\
\text { da garganta, ação antivomitiva, ani- } \\
\text { inflamatória, antirreumática, antiviral e } \\
\text { atividade antitussígena. }\end{array}$ \\
\hline
\end{tabular}

Fonte: Dados coletados pelos alunos do PICMEL (2015) elaborados com base em Lorenzi e Matos (2008).

As plantas medicinais encontradas com maior frequência nas propriedades foram: Cymbopogon citratus $(78,6 \%)$, Achyrocline atureioides $(64,3 \%)$, Chamomilla recutia e Citrus sinensis $(50,0 \%)$, Vernonia condensata $(35,7 \%)$ e Aloe vera, Mikania glomerata e Mentha spp. (28,6\%). O local de plantio das mesmas variou nas propriedades, $42,9 \%$ afirmam plantar em diferentes locais da propriedade, mesmo percentual que afirma plantar hortas e 14,3\% afirmam plantar próximo à casa.

Em um estudo de Salvi et al. (2016) demonstram que as principais plantas medicinais utilizadas para controle do diabetes, na mesma região de estudo dos BIC Jr., são também citadas pelos produtores rurais entrevistados no projeto PICMEL; no entanto, não cultivadas pelos mesmos. Salvi et al. (2016) constataram que $88 \%$ dos participantes mencionaram ter algum conhecimento quanto ao uso de chás para o tratamento do diabetes e a maioria 
relatou conhecer mais do que uma planta medicinal. Entre os participantes da pesquisa, $56 \%$ relataram ter feito uso de alguma planta medicinal considerada hipoglicemiante para controle do diabetes sendo que as mais citadas foram: Cissus verticilata $\mathrm{L}$. Nicolson \& C.E.Jarvis (insulina vegetal com 35,71\%), Bahunia forficata Link (pata-de-vaca com 28,57\%) e Syzygium cumini (L) Skeels (jambolão com $17,85 \%)$.

Os dados obtidos foram tabulados pelos BIC Jr. que realizaram apresentação do projeto e dos resultados em sua escola. Um artigo sobre otrabalho desenvolvido foi apresentado no Congresso Latino Americano Interdisciplinar Orientado ao Adolescente (CLIOA), em Porto Alegre. Os alunos elaboraram resumos que foram apresentados na Mostra de Ensino, Extensão e Pesquisa (MEEP) e no Salão de Iniciação Científica, Tecnológica e de Inovação (SICTI), conquistando boas avaliações. Os BIC Jr. também confeccionaram o herbário com os exemplares das plantas medicinais encontradas nas propriedades e $\mathrm{o}$ levaram para a escola, como material didático de consulta dos demais colegas e também dos professores. No decorrer das saídas à campo e estudos, os alunos tiveram a iniciativa de revitalizar o horto medicinal, denominado "relógio dos chás", na Escola. Mobilizaram colegas, professores e demais alunos para o preparo da terra, plantio das mudas e também explanaram sobre o uso e forma de utilização de cada espécie plantada na escola.

$\mathrm{O}$ envolvimento dos alunos do ensino fundamental em projetos de pesquisa e em atividades de campo mostra-se muito positivo, pois os mesmos tendem a desenvolver as habilidades de analisar, interpretar, compreender, opinar e argumentar de forma crítica o que assimilaram a partir das leituras e experiências convividas. Algumas habilidades e qualidades são despertadas pelos alunos durante a iniciação científica, seja através do trabalho de pesquisa ou das saídas a campo, e que estas habilidades farão parte futuramente do perfil profissional do estudante. Em um estudo feito com alunos de Cursos de Ciências Biológicas, 77,8\% destes consideram as saídas à campo a principal atividade que contribuiu para a aprendizagem (REMPEL et al., 2016). As atividades de campo são consideradas importantes recursos para a ação pedagógica, pois apresentam grande potencial para estimular a argumentação e mediar a construção do conhecimento científico do aluno conjuntamente com as aulas desenvolvidas no espaço formal de ensino (GRANDI; MOTOKANE, 2009).

$\mathrm{Na}$ pesquisa de Rempel et al. (2016) é destacado que alunos participantes do estudo observaram a relevância das atividades em campo para o seu processo de aprendizagem assim como relatado pelos BIC Jr. do projeto PICMEL, corroborando com os trabalhos desta área (LOPES; ALLAIN, 2002; SENICIATO; CAVASSAN, 2004; COMPIANI, 2007; VIVEIRO; DINIZ, 2009; ROCHA, 2009; OLIVEIRA; ASSIS, 2009).

Para Compiani (1991), o campo é um excelente "ambiente de ensino", que pode auxiliar na aprendizagem dos alunos, pois proporciona o contato 
direto com os objetos e os fenômenos concretos que estão sendo estudados. $\mathrm{O}$ contato direto com o meio permite que o aluno perceba os fenômenos em sua interação e a natureza não fragmentada, mas reconhecer as relações que existem, que se concretizam.

A Educação Ambiental, mesmo sendo "componente essencial e permanente da educação nacional, devendo estar presente, de forma articulada, em todos os níveis e modalidades do processo educativo, em caráter formal e não-formal" (BRASIL, 1999, p. 1) desde 1999, é muitas vezes trabalhada na Educação Básica superficialmente. Em muitas escolas são desenvolvidos projetos que não despertam o interesse do aluno, pois o mesmo não se sente responsável pela ação ou desconhece seu objetivo. Em estudo de Rempel e Guerra (2009), as atividades ou experiências que são realizadas nas escolas com maior frequência (54\%) têm o enfoque na reciclagem e coleta seletiva de lixo. No estudo desenvolvido no projeto PICMEL observa-se que há inúmeras possibilidades de trabalho que envolvem os alunos, desenvolvendo sua autonomia, despertando interesse por questões ambientais e que são de interesse deles e, por consequência, de toda a escola.

\section{CONCLUSÃO}

A iniciação científica é importante no processo de formação da vida escolar do estudante e no desenvolvimento da pesquisa. A habilidade de comunicar-se, de coletar informações e delas retirar algum conhecimento, apontando para os passos seguintes da pesquisa, é o que diferencia, e cada vez mais diferenciará as pessoas na sociedade. Os BIC Jr. participantes do projeto PICMEL demonstraram habilidade para estudos aprofundados em Botânica, capacidade de comunicação com produtores rurais e no meio científico, uma vez que apresentaram os resultados da pesquisa em eventos científicos, e também desenvolveram autonomia, demonstrada na iniciativa de construção de um herbário para ser levado à escola e revitalização do horto medicinal.

\section{AGRADECIMENTO}

Agradecimento para à CAPES, à FAPERGS, à Univates e aos produtores participantes da pesquisa.

\section{REFERÊNCIAS}

BEAUCHAMP, J.; PAGEL, S. D.; NASCIMENTO, A; R; do. Indagações sobre currículo: diversidade e currículo. Brasília: Ministério da Educação, Secretaria de Educação Básica, 2007.

BRASIL. Lei n ${ }^{\circ}$ 9.795, de 27 de abril de 1999. Dispõe sobre a educação ambiental, institui a Política Nacional de Educação Ambiental e dá outras providências. Diário Oficial da União, Brasília, 28 de abril de 1999. 
CAVALHEIRO, P. Organização e planejamento de atividades de monitoria para o ensino de ciências no nível fundamental. Acta Científica - Ciências Humanas. São Paulo, v. 2, n. 13, p. 27-39, 2007.

CAVALHEIRO, P.; DEL PINO, J. C. Aprendizagem e cooperação em atividades de monitoria para o ensino de ciências no nível fundamental. Experiências em Ensino de Ciências, Cuiabá, v.2, n.3, p. 17-33, 2007

COMPIANI, M. A relevância das atividades de campo no ensino de Geologia na formação de professores de Ciências. Cadernos IG/UNICAMP, v.1, n.2, p.2-25, 1991.

DEL PINO, J. C. Atividades de monitoria para o ensino de ciências no nível fundamental e médio. Projeto de pesquisa encaminhado em atendimento ao Edital Fapergs/Capes 15/2013.

GRANDI, L.; MOTOKANE, M. Reflexões sobre as características de um trabalho de campo que estimule a argumentação e a enculturação científica dos alunos. Enseñanza de las Ciencias, Número Extra VIII Congreso Internacional sobre Investigación em Didáctica de las Ciencias, Barcelona, p. 849-852, 2009.

FANTINEL, L. M. Práticas de campo em fundamentos de geologia introdutória: papel das atividades de campo no ensino de fundamentos de geologia no curso de geografia. (Dissert. mestrado em Educação Aplic. Geociências) Campinas: Inst. Geociências UNICAMP. 2000.

LOPES, G. C. L. R.; ALLAIN, L. R. Lançando um olhar crítico sobre as saídas de campo em biologia através do relato de uma experiência. In: ENCONTRO PERSPECTIVAS DO ENSINO DE BIOLOGIA, 8, 2002, São Paulo. Anais... São Paulo: FEUSP/USP, 2002. p. 6.

LOPES, R. de C. S. A relação professor-aluno e o processo ensino-aprendizagem. Ponta Grossa: UEPG, 2008. Produção Didática apresentada ao Programa de Desenvolvimento Educacional - PDE, Secretaria de Estado da Educação do Paraná.

LORENZI, H.; MATOS, F. J. de A. Plantas Medicinais no Brasil: nativas e exóticas. 2.ed. Nova Odessa: Instituto Plantarum, 2008.

OLIVEIRA, C. D. M.; ASSIS, R. J. S. Travessias da aula em campo na geografia escolar: a necessidade convertida para além da fábula. Educação e Pesquisa, v. 35, n.1, p. 195209, 2009.

REMPEL, C.; STROHSCHOEN, A. A. G.; GERSTBERGER, A.; DIETRICH, F. Percepção de alunos de Ciências Biológicas sobre diferentes metodologias de ensino. Signos, Lajeado, ano 37, n. 1, p. 82-90, 2016.

REMPEL, C.; GUERRA, T. Ações de educação ambiental em escolas de Educação Infantil e séries iniciais do Ensino Fundamental no Vale do Taquari-RS. Caderno pedagógico, Lajeado, v. 6, n. 1, p. 105-124, 2009 
SALVI, L. C.; BERSCH, B.; REMPEL, C.; STROHSCHOEN, A. A. G. Percepção de indivíduos com Diabetes Mellitus sobre a utilização de Bahinia forficata Link (Fabaceae). Contexto \& Saúde, Ijuí, v. 16, n. 30, p. 55-63, jan./jun. 2016.

SENICIATO, T.; CAVASSAN, O. Aulas de campo em ambientes naturais e aprendizagem em Ciências - um estudo com alunos do ensino fundamental. Ciência \& Educação, v. 10, n. 1, p. 133-147, 2004.

VIVEIRO, A. A.; DINIZ, R. E. S. As atividades de campo no ensino de ciências: reflexões a partir das perspectivas de um grupo de professores. In: NARDI, R. org. Ensino de ciências e matemática, I: temas sobre a formação de professores [online]. São Paulo: Editora UNESP; São Paulo: Cultura Acadêmica, 2009. 258 p. ISBN 978-857983-004-4. Available from SciELO Books <http://books.scielo.org>. 